\title{
The design and development of covalent protein-protein interaction inhibitors for cancer treatment
}

\author{
Sha-Sha Cheng ${ }^{1 \dagger}$, Guan-Jun Yang ${ }^{1 \dagger}$, Wanhe Wang ${ }^{2,3}$, Chung-Hang Leung ${ }^{1 *}$ (D) and Dik-Lung Ma ${ }^{2 *}$
}

\begin{abstract}
Protein-protein interactions (PPIs) are central to a variety of biological processes, and their dysfunction is implicated in the pathogenesis of a range of human diseases, including cancer. Hence, the inhibition of PPIs has attracted significant attention in drug discovery. Covalent inhibitors have been reported to achieve high efficiency through forming covalent bonds with cysteine or other nucleophilic residues in the target protein. Evidence suggests that there is a reduced risk for the development of drug resistance against covalent drugs, which is a major challenge in areas such as oncology and infectious diseases. Recent improvements in structural biology and chemical reactivity have enabled the design and development of potent and selective covalent PPI inhibitors. In this review, we will highlight the design and development of therapeutic agents targeting PPIs for cancer therapy.
\end{abstract}

Keywords: Protein-protein interaction, Covalent inhibitors, Cancer therapy

\section{Background}

The protein-protein interaction (PPI) is defined as a physical link between a protein and its partner(s) [1-3]. These connections may display a range of heterogeneities and complexities in macromolecular structures, forming protein dimers, multicomponent complexes, or long chains [4]. The interaction between protein subunits can be transient or permanent, identical or heterogeneous, and specific or nonspecific $[3,5,6]$. There are nearly 650,000 PPIs in humans, and this number continues to increase as more interaction networks become discovered [3, 7]. The function of proteins plays an essential role in the context of PPI networks [5]. For example, the PPI system connects different enzymes with their protein substrates and regulates the activity of

\footnotetext{
* Correspondence: duncanleung@um.edu.mo; edmondma@hkbu.edu.hk †Sha-Sha Cheng and Guan-Jun Yang contributed equally to this work. ${ }^{1}$ Institute of Chinese Medical Sciences, State Key Laboratory of Quality Research in Chinese Medicine, University of Macau, Macao, SAR, China ${ }^{2}$ Department of Chemistry, Hong Kong Baptist University, Kowloon 999077, Hong Kong, China

Full list of author information is available at the end of the article
}

proteins [5]. Twenty percent of proteins exist in network hubs and interact with at least 24 partners [8]. Proteins occupy almost half of the dry mass of a cell, and the disruption of PPIs often causes diseases, including cancer $[9,10]$. Hence, research on PPI plays a central role in progressing our understanding of molecular biology and human diseases, as well as for developing new therapeutic agents in drug discovery $[6,11,12]$.

The abnormal regulation of PPIs contributes to the majority of cancers. PPIs are involved in all phases of oncogenesis, from cell proliferation, cell survival, and inflammation to invasion and metastasis (Fig. 1) [13, 14]. Understanding the molecular mechanisms of PPIs is therefore crucial for developing accurate methods for the prevention, diagnosis, and treatment of cancers. The contact interface between two proteins is the structural foundation of their interaction. Understanding the contact region between proteins will help to elucidate their functions in interaction networks. It should be noted that similar or overlapping interfaces can be promiscuous and be employed many times in hub proteins [15]. The cancer-related proteins are abnormally expressed

(c) The Author(s). 2020 Open Access This article is licensed under a Creative Commons Attribution 4.0 International License, which permits use, sharing, adaptation, distribution and reproduction in any medium or format, as long as you give appropriate credit to the original author(s) and the source, provide a link to the Creative Commons licence, and indicate if changes were made. The images or other third party material in this article are included in the article's Creative Commons licence, unless indicated otherwise in a credit line to the material. If material is not included in the article's Creative Commons licence and your intended use is not permitted by statutory regulation or exceeds the permitted use, you will need to obtain permission directly from the copyright holder. To view a copy of this licence, visit http://creativecommons.org/licenses/by/4.0/ The Creative Commons Public Domain Dedication waiver (http://creativecommons.org/publicdomain/zero/1.0/) applies to the data made available in this article, unless otherwise stated in a credit line to the data. 


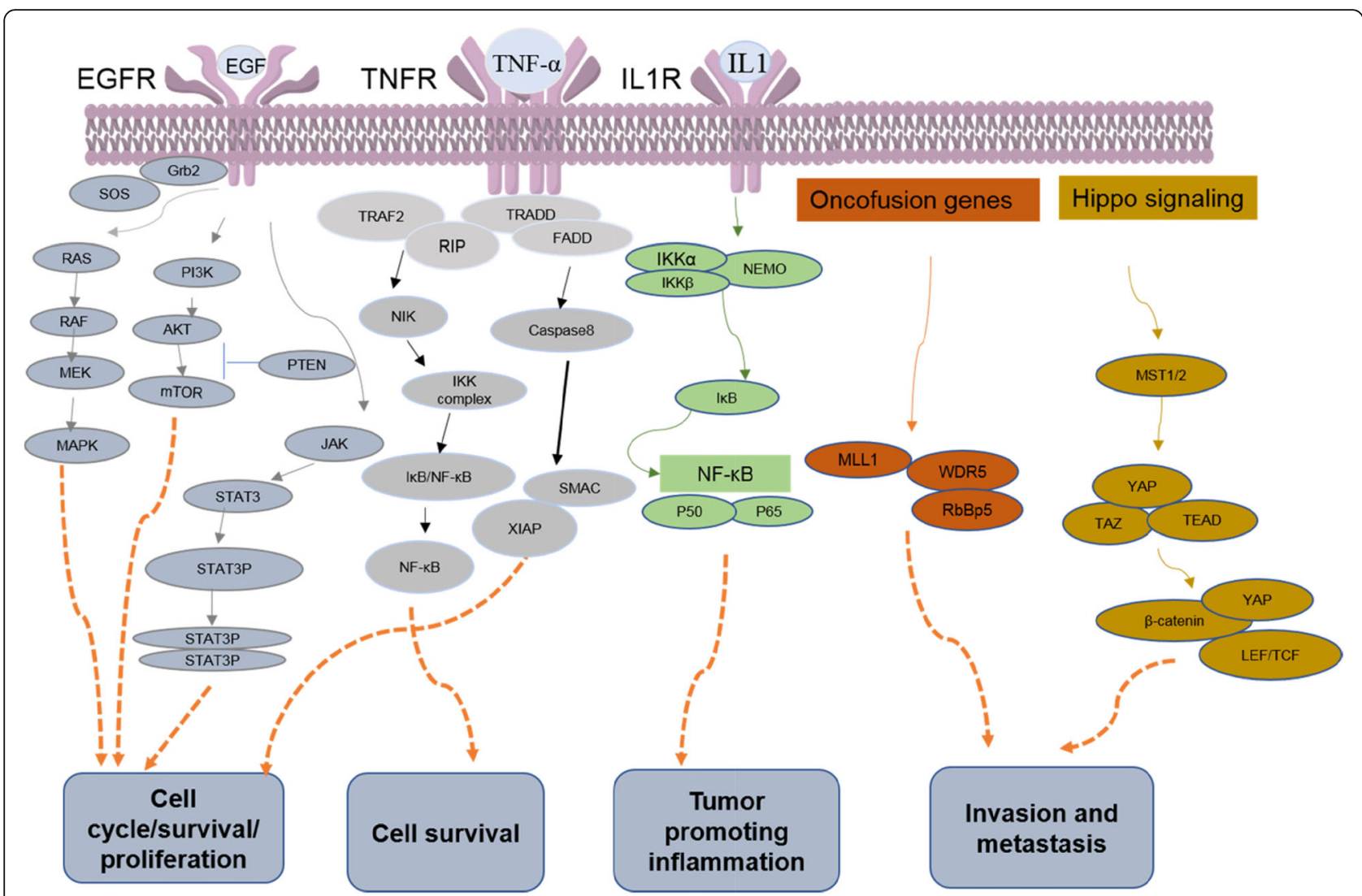

Fig. 1 Oncogenic PPI networks that are associated with the hallmarks of tumorigenesis. It should be noted that some PPI networks regulate global mechanisms of cell growth and their relationship to cancer remains to be verified

(overexpressed, low expressed, or mutant) in cancer cells compared to normal cells. For example, S100A13 overexpression contributed to tumor metastasis and poor survival in patients with early-stage non-small cell lung cancer [16]. Low TMEFF2 expression was associated with larger tumor size and advanced stage and poor differentiation in pancreatic cancer cells [17]. It was reported that more than $50 \%$ of cancer patients have p53 mutations, which may cause cancer therapy resistance, and the underlying mechanism is poorly understood [18]. Cancer-associated protein-protein interaction network which is involved in cancer development tend to interact with each other to form a cancerspecific interaction network, and it is important for acquisition and maintaining characteristics of cancer essential for cell transformation [19, 20]. Deeper investigations of protein-protein interfaces relevant to human oncogenesis and cancer-associated protein-protein interaction networks have shown that cancer-related proteins are smaller, more planar, more charged, and less hydrophobic binding sites than non-cancer-related proteins and they tend to show lower affinity and higher specificity for cancer-associated PPI networks. Moreover, cancer-related proteins often interface with their binding partners using distinct surfaces, corresponding typically to multi-interface hub [21]. Therefore, targeting PPIs can be a viable approach for cancer treatment since the aberrant activity of these networks often directly leads to tumor progression.

Compared with targeting enzymes or receptors, however, the development of molecules targeting PPIs has been challenging [22-24]. PPIs have relatively large and amorphous interfaces, rather than small and well-defined crevices. Recent efforts in developing clinical PPI inhibitors have focused on targeting "hotspots" that typically span 250-900 $\AA^{2}$ of the PPI interface [25]. Generally, there are three different classes of PPI: short continuous peptide epitopes, secondary structural epitopes, and tertiary structural epitopes. Short continuous peptide epitopes consist of continuous linear sequences of about 6-9 amino acids (Fig. 2a) [26]. Secondary structural epitopes can bind as single unit, for example, a single face of an $\alpha$-helix binding to a hydrophobic groove of complementary residues (Fig. 2b) [27, 28]. In the tertiary structure of epitopes, the binding interface is not continuous and requires multiple sites to form the PPI interface [24]. Compared with primary and secondary structure of epitopes, the interfaces of tertiary epitopes are more dynamic and prevalent (Fig. 2c) [29]. Targeting the tertiary structural epitopes of PPIs with chemical agents is challenging, but may also represent a vast area of opportunity as 


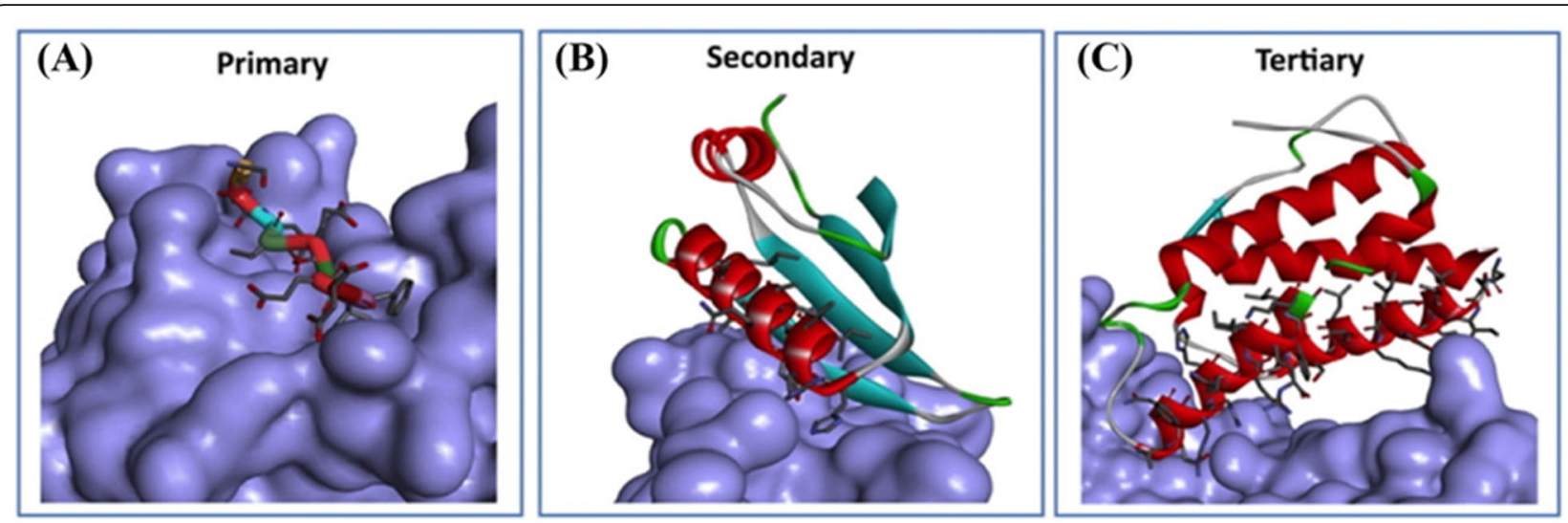

Fig. 2 The crystal structure of three different classes of PPIs. a Linear sequences comprise primary peptide epitopes (e.g., LM of DNA polymerase III bound to the binding pocket of the SC (PDB: 3D1F)). $\mathbf{b}$ The secondary structure of epitopes binds as a single unit, e.g., an a-helix (NusB-NusE PPI (PDB: 3R2C)). $\mathbf{c}$ In tertiary structural epitopes, the binding interface is not continuous and both sides of PPI interface are needed (e.g., IL-2/IL2Ra PPI (PDB 1Z92))

well as they tend to be much more dynamic than the primary and secondary class epitopes. To date, many PPI modulators have been developed and some of these have even successfully entered the clinic [30-33]. PPI inhibitors can be classified into small molecules, antibodies, peptides, or recombinant proteins. As PPI interfaces are generally wide, therapeutic antibodies have attracted attention as candidates for PPI inhibition $[34,35]$. On the other hand, small molecules are much cheaper and easier to produce compared to protein- or peptide-based drugs and may tolerate a wider range of administration modes (e.g., oral), which makes them favorites of pharmaceutical chemists [34]. But there are three obstacles for targeting PPIs with small molecules. First, the contact interfaces of PPIs typically contain an array of polar and non-polar interactions spread over a large area $\left(1500-3000 \AA^{2}\right)$ [36]. Unless the interaction hotspot can be identified, a small molecule with a reduced footprint has difficulty achieving tight binding owing to insufficient interactions. Secondly, protein-protein interfaces are usually flat. Without concavity, a small molecule is limited to only contact one side of the binding site, which is comparatively less effective compared with inserting into a deep groove. Thirdly, targeting PPIs with covalent inhibitors is not possible if an appropriate nucleophilic residue is not available in the protein-binding interface, especially free cysteine, lysine, or methionine residues [32, 33]. Therefore, targeting alternative nucleophilic sites, including tyrosine, threonine, serine, and histidine, should be investigated to offer new avenues for covalent inhibitor development. Aided by recent advancements in structural biology and chemistry, covalent inhibitors have emerged as a potentially effective approach towards PPI inhibition [37, 38]. Studies have indicated that covalent drugs are less likely to promote resistance [39], which could be important for diseases such as cancer and infectious diseases where drug resistance is a major challenge. Covalent inhibitors are generally comprised of a specificity group to recognize the target protein and a functional "warhead" that forms a covalent linkage with the protein. Compared with noncovalent inhibitors, covalent PPI inhibitors can have the advantages of sustained inhibition and longer residence times, as covalently bound PPI targets are persistently inhibited until protein degradation and regeneration [40]. Additionally, covalent inhibitors can exhibit high selectivity for proteins with non-conserved residues between variant forms or protein family members [41]. This can be a significant advantage in cancer treatment, because point mutations of target proteins often generate resistance to drug treatment [42, 43]. Thus, covalent inhibitors targeting PPIs offer the potential ability for expanding the therapeutic range [44]. However, the strong binding of covalent inhibitors can also produce drawbacks. In the 1970s, researchers reported that covalent drugs produce hepatotoxicity resulting from off-target effects via unselectively modifying non-target proteins with their highly reactive groups $[37,45]$. Meanwhile, whether inhibitors are covalent or non-covalent, side effects arising from idiosyncratic risks are always an issue that has to be considered in drug research and development [46, 47]. Given the potential of covalent drugs, the advantages and disadvantages of covalent PPI inhibitors should be carefully judged and weighed by practitioners in drug discovery.

\section{Strategies to design and develop covalent PPI inhibitors Different strategies to design covalent PPI inhibitors}

Different strategies are needed to design covalent PPI inhibitors compared to non-covalent inhibitors [48-50]. Covalent inhibitors traditionally target cysteine; however, their natural abundance is low and these residues have unique reactivity in proteome. Therefore, new strategies are imperative to design and develop to target interaction sites that lack reactive cysteine residues. The following sections discuss methods for the development of 
covalent PPI inhibitors, including structure-guided design, activity-based profiling, and covalent docking.

\section{Structure-guided design of covalent inhibitors}

Advancements in structural biology have aided the structure-guided design of non-covalent and covalent inhibitors alike [51]. Covalent PPI inhibitors typically react with a side chain of an amino acid that is located within the binding site to form a covalent bond, which are usually (but not always) irreversible. In traditional drug discovery, the linkage between a target and its corresponding disease drives the development of therapeutic molecules against the target. For the structure-based design of covalent inhibitors, an alternative prospective strategy has been considered that first identifies potential proteins that could be targeted by covalent inhibitors, which are then consolidated into target subsets. Recently, a new technology to identify covalent fragments has emerged, which uses reactive covalent ligands to identify covalent targets in phenotypic or target-based screens [52].

Reactive cysteine residues on proteins have high nucleophilicity, which enables covalent binding with electrophilic small molecules [53, 54]. Therefore, reactive cysteine residues at the PPI site are considered as a common characteristic for the design of covalent PPI inhibitors. Computational tools can detect covalent binding site through several methods: (1) binding site prediction, (2) hydrogen bond frequency analysis, and (3) covalent binding site detection [55]. Meanwhile, comprehensive databases including targetable cysteine and known covalent inhibitors can be manually curated [54-57]. However, it should be noted that covalent inhibitors may modify many available residues in a target, and some proteins may be more susceptible to this than others. Therefore, it is vital to accurately pinpoint a residue's location in the target as well as in similar binding sites as this could influence the agents' selectivity.

Interaction binding pockets in protein structures can also be identified through computational algorithms [58]. Using a structure identification approach, various potential interaction pockets can be ranked in terms of the surrounding residues. There are some successful cases demonstrating that analyzing the residues around the PPI binding site can provide useful information for covalent inhibitor development. For instance, the peptides second mitochondria-derived activator of caspase (SMAC) and $\mathrm{N}$-terminal tetrapeptide of the sequence Ala-Val-Pro-Phe (AVPF), discovered through structure-based approaches, have high stability, affinity, and cell permeability, and ultimately increase the drug-likeness of the original tetrapeptide. Some potential drug-like peptides of SMAC AVPF have been applied in various treatment areas and some have even entered clinical trials [59]. This successful case of structure-based design provides a promising prospective for designing covalent inhibitors against PPIs. Studies on structural and cellular reveal that when mitochondrial release into the cytosol, the activation of SMACs exposes the N-terminal tetrapeptide of the sequence AVPF. The tetrapeptide mediates its interactions with various members of the IAP family, including the Xlinked inhibitor of apoptosis protein (XIAP). In addition, Lys-covalent inhibitors have been designed with a benzamide-sulfonyl fluoride warhead to target the BIR3 domain of XIAP [60, 61].

In another study, the structure-based biophysical and biochemical approaches were used to develop different kinds of warheads which can easily form covalent adducts with alternative amino acids such as histidine, threonine, serine, and tyrosine [62]. It was found that aryl-fluoro sulfate electrophiles can form covalent bonds with Lys, Tyr, and His residues in PPIs [61]. With the tremendous progress and resurgence for covalent drugs, these successful cases present valuable and novel ideas for covalent PPI inhibitors and suggest the possibility for extending the target cysteinome range to other residues.

\section{Activity-based protein profiling of covalent inhibitors}

Activity-based protein profiling (ABPP) is a type of chemical proteome method that aims to evaluate the on-target and off-target activities of a covalent drug. In ABPP, activity-based probes (ABPs) are used to visualize the target protein in a mechanism-based fashion [63]. By targeting only the activated residue on the protein, only the catalytically active form of enzyme will be covalently labeled by the probe. In addition, ABPP methods are also applied to study protein activity at different stages of diseases, recognize and characterize various function of proteins including unknown ones, identify covalent linkages between protein targets and natural products, and identify potential inhibitors of protein [64]. In order to develop a site-specific technique for quantification of reactivity, researchers have developed a new method termed isotopic tandem orthogonal proteolysis (isoTOP)-ABPP [65]. A chemical-proteomic employing of isoTOP-ABPP was reported to analyze the cysteine activity of complicated proteomes (Fig. 3) [64]. IsoTOP-ABPP methods provide two opportunities for developing covalent inhibitors of PPI for drug discovery. Firstly, the method enables the identification of cysteines that can be targeted by covalent modification to regulate protein activity. Secondly, the technique can identify related targets in the cell in order to evaluate the promiscuity of small molecules, electrophilic groups, or natural products [65]. This assay can also be adapted to a competition mode, by challenging ligandable sites with both covalent drugs and reactive cysteines in order to aid rapid target discovery as well as discover new druggable hotspots that can be targeted by covalent drugs. In our view, the development of PPI covalent inhibitors could be 


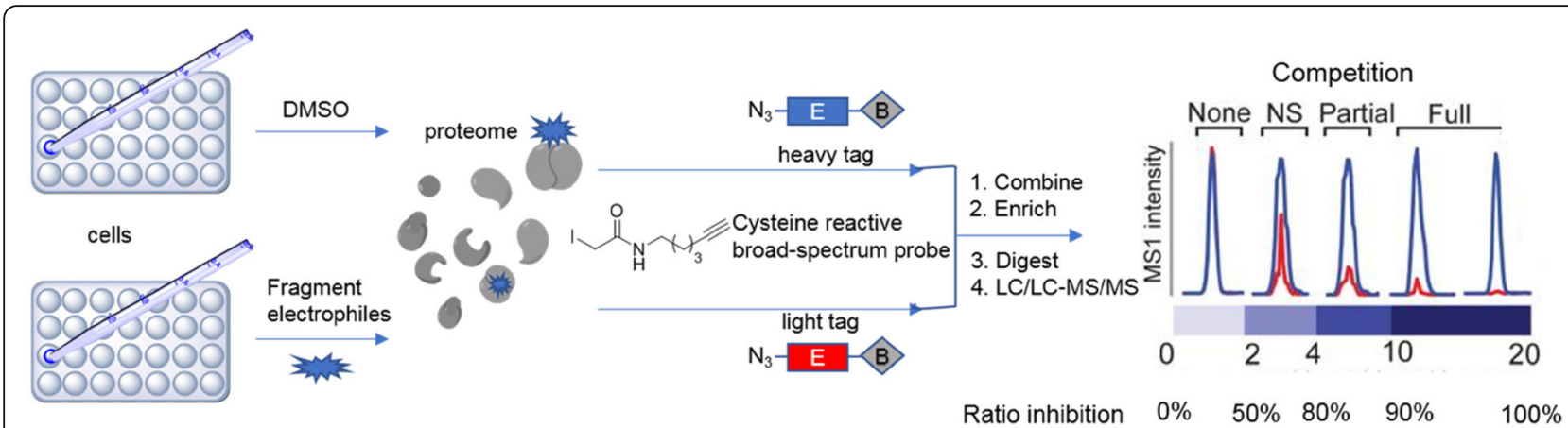

Fig. 3 The general workflow of the isoTOP-ABPP platform. The cell proteome is labeled with a cysteine-reactive probe, and then samples are conjugated to TEV protease-cleavable biotin tags (heavy (blue) and light (red)). Competition ratios are calculated following protein digestion and multidimensional liquid chromatography-tandem mass spectrometry

accelerated by combining the platforms of isoTOP-ABPP with cysteine-reactive ligand libraries [66]. The approach can lead to the identification of covalent inhibitors targeting novel and complicated PPI binding sites, as well as for studying for cysteine reactivity in biological systems. Furthermore, other amino acids with reactive functional groups can also be studied using the chemical-proteomic platform of isoTOP-ABPP in order to identify new druggable hotspots in PPI. For example, dichlorotriazines have a tendency to bind with lysine [67], so they can be exploited as reactivity-based probes in ABPP platforms to detect and identify covalent inhibitors of PPIs [68]. Recently, dichlorotriazine-based covalent ligands were studied for their effects on triple-negative breast cancer cell survival [69]. The compound KEA1-97, identified using a ABPP-based chemoproteomic platform, targeted the lysine-72 site of thioredoxin to disrupt its PPI with caspase-3, leading to the activation of apoptosis [70]. Thus, expanding the application of ABPP with covalent ligand libraries targeting different amino acids (lysine, cysteine, methionine) could open new avenues for identifying covalent PPI drugs in the future. Moreover, these strategies also allow the identification of druggable hotspots and PPI targets for various diseases.

\section{Covalent docking}

Computational tools can aid in the understanding of the complex interactions in biological systems [71]. The feasibility of hotspots as well as therapeutic targets can be evaluated through different computational strategies, for instance, molecular dynamics (MD), homology modeling, quantitative structure-activity relationships (QSAR), and molecular docking $[72,73]$. However, most methods were initially developed for noncovalent inhibitors. Some of these can be applied for covalent drug design; however, configurations may have to be changed to allow for the formation of covalent bonds between the substrate and ligands [71].
Various kinds of algorithms have been developed to model covalent bonds between inhibitors and protein targets. In molecular docking system, the relative binding affinity of inhibitors and their binding mode can be predicted using the following two-step methodology. First, the conformational space is sampled for both the covalent ligand (usually flexible) and the protein (sometimes flexible). Second, the potential binding modes between the covalent ligands and the complexes are analyzed. Different covalent docking programs are available to identify covalent inhibitors of PPIs, such as MOE, CovDock, AutoDock4, FITTED, GOLD, and ICM-Pro [73]. Different protocols have been generated to covalently dock small molecules to biomolecular targets. However, the majority of covalent algorithms are limited to accurately calculating the binding energy between a nucleophilic protein and an electrophilic small molecule (Fig. 4) [74]. The "link atom" approach in GOLD is one of the most common routines for identifying possible linkages between a covalent ligand and the target protein in order to mimic the progress of covalent binding [73]. Autodock4 docks covalent inhibitors using either the "two-point attractor method" or "flexible side chain-based modification." The former identifies and mimics the alkylating molecule as a free ligand in order to consider covalent bond formation between the ligand and an alkylated residue. The latter involves sampling the space around a single flexible side chain in order to assess the interaction between the protein attachment point and the covalent ligand [75]. Covalent docking also has some disadvantages, such as poor scoring functions, and limitations in torsional entropy, speed, and accuracy. The flexibility of side chains also needs to be accurately modeled in order to reflect the reality of the PPI binding site [76, 77]. Moreover, covalent docking requires substantial preparatory work that is not easily amenable to automation. The flexibility of side chains is another important factor to consider for covalent docking [76].

In the literature, covalent docking has been used to identify covalent PPI inhibitors in drug discovery. For 


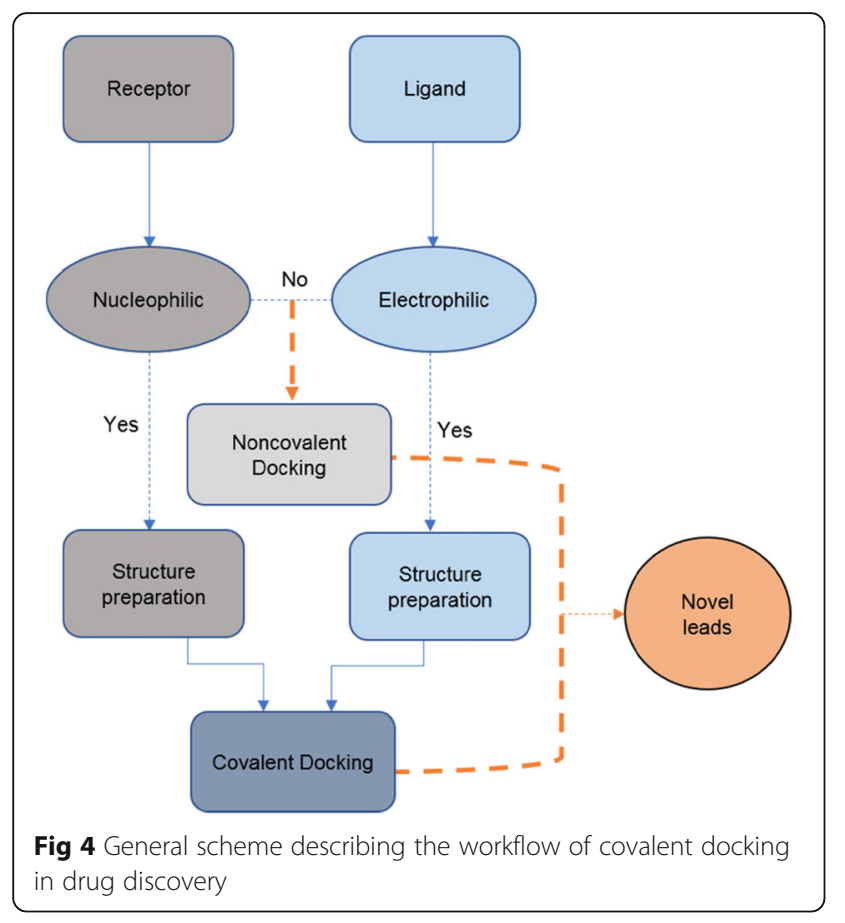

example, the natural product andrographolide contains a reaction $\alpha, \beta$-unsaturated lactone group, which targeted the nucleophilic Cys62 on the p50 subunit of NF-кB [78]. After performing computer docking, site-directed mutagenesis, and mass spectrometry, the researchers determined that the initial non-covalent interaction between inhibitors and residues on binding site are important for andrographolide covalent incorporation. This highlights the important fact that apart from the electrophilicity of the ligand, the redox environment and non-covalent interactions within the binding site should also be taken into account when designing covalent PPI inhibitors.

Some of the techniques for discovering covalent PPI inhibitors described above also have their own limitations. For example, the isoTOP-ABPP method is limited by the range of identifiable cellular cysteines and cannot evaluate the selectivity of compound in the total cellular cysteinome. Cell lysates are usually treated under non-reducing conditions, and so, some reactive cysteines may oxidize or aggregate. These shortcomings could lead to poor selectivity of compounds and aggregation or oxidation of reactive cysteines. These limitations can potentially be overcome by developing new cysteine-reactive electrophiles and other cell-based profiling methods [64]. Covalent docking also has some disadvantages, such as poor scoring functions, and limitations in speed and accuracy.

\section{Screening methods for developing covalent PPI inhibitors} In the past few years, a large number of covalent screening technologies have been developed and implemented for drug discovery. In the context of covalent PPI inhibitors, a variety of covalent high-throughput screening (HTS) methods can be used to complement conventional PPI screening assays in order to accelerate the identification of covalent PPI inhibitors.

The covalent binding of low molecular weight fragments can be identified by mass spectrometry or X-ray crystallography. X-ray crystallography allows for the direct verification of hits identified by the primary screening, since the crystal structure allows direct determination of the binding position of the fragment. Together with mutational analysis, NMR and X-ray crystallographic methods can be employed to identify hot spots in PPIs. After confirming the covalent binding mode of the fragment and identifying the hotspots targeted by the fragment, the affinity and selectivity of the compound can be further improved using traditional medicinal chemistry principles. Generally, covalent fragments have a relatively simple structure, and the reactivity of the fragment is the main factor driving binding activity of the PPI target. However, an excessively high binding reactivity could also increase the risk of off-target toxicity. During optimization, a decrease in the reactivity of the covalent warhead may be required to improve selectivity for a particular residue over others $[40,79]$.

Besides screening fragment-sized covalent ligands, it is also possible to perform HTS on a larger number of larger molecule weight and more drug-like covalent inhibitors. Having a larger library enables testing of a wide range reactivity of warheads, including those that may form reversible linkages to the target. In one example, covalent PPI inhibitors were identified against RAS G12C [80]. After identifying the hit of covalent inhibitors through fragmentbased screening, a structure-based drug design strategy was used to improve their selectivity and efficiency. However, a limitation of HTS for covalent screening is that a large number of covalent inhibitors are needed in the library. Moreover, enough protein construct and appropriate identification methods are also essential for screening covalent binding between protein targets and PPI inhibitors. Covalent inhibitors targeting PPIs can be also screened through phenotypic or "black-box" methods. Many classic covalent inhibitors have been identified by this method. In order to evaluate the phenotypic changes at the cellular level, an appropriate cellular assay is required. There are two main advantages of the phenotypic screening method for identifying covalent PPI inhibitors. Firstly, this technique identifies cellactive compounds directly. Secondly, the biological target does not have to be known before screening [81]. However, disadvantages are that a sufficiently large covalent library is needed and that the target will have to be eventually identified in order to optimize the selectivity of the drug.

Recently, the quantitative irreversible tethering (qIT) method has been reported for screening PPI covalent inhibitors. This approach is based on kinetic selectivity 
maximization in order to identify small molecule covalent inhibitors with cysteine reactivity. In this assay, thiol consumption is analyzed in a high-throughput format via fluorogenic thiol quantification (FTQ), in order to determine the kinetics of electrophile-thiol conjugation (Fig. 5) [82]. Control thiols and parallel dynamics analysis can also be used to evaluate the heterogeneous reactivity of covalent electrophilic ligands. Using this method, hit fragments targeting the binding pocket of the protein can be rapidly recognized. Importantly, the site on the protein can be predefined and is not limited by protein function [83]. Thus, the FTQ can be a simple and cost-effective assay for screening covalent inhibitors of PPIs. The above screening strategies can be used to identify covalent inhibitors of PPI targets. The choice of method used will depend on the number of compounds in the library, knowledge of structural information of the inhibitors, and the type of target itself. After screening, covalent inhibition can be confirmed by testing for the time dependency of the IC50 value. If there is no change in the IC50 in the time-dependent assay within a specified time range of the experiment, then it can be inferred that covalent binding between the inhibitor and protein does not take place. This could be, for example, due to the low reactivity of the targeted cysteine residue which hinders covalent bond formation. Looking toward the future, there is still significant room for the development of covalent PPI inhibitors that target non-catalytic, noncysteine residues. Computational techniques could play an important role in advancing this area by identifying novel hotspots and accelerating the process of inhibitor design.

\section{Successful covalent PPI inhibitors in cancer therapy}

Although PPIs represent a large class of potential therapeutic targets, the design of effective and selective PPI inhibitors is still challenging. An alternative approach of covalent targeting PPIs has attracted increasing attention as a method of developing more potent PPI inhibitors. In recent years, a number of covalent PPI inhibitors have been approved by the US Food and Drug Administration (FDA) (Table 1). In the specific field of oncology, one covalent PPI inhibitor has been approved by the FDA, while others have entered clinical trials [84, 89, 91-93]. One recent example is the covalent inhibitor $\mathrm{COH} 000$, a highly specific allosteric inhibitor of the SUMO (small ubiquitin-related modifier) E1 enzyme, an anticancer target [88]. Interestingly, $\mathrm{COH} 000$ binds to a cryptic pocket within SUMO E1 that is separate from its active site and which had been observed to be buried in previous structures of the enzyme. It was hypothesized that the SUMO E1 is in constant structural flux and that $\mathrm{COHOOO}$ could lock the enzyme into an inactive state that has not been observed before. Most importantly, $\mathrm{COHOOO} \mathrm{has} \mathrm{notable} \mathrm{anticancer} \mathrm{in} \mathrm{vitro} \mathrm{colorectal} \mathrm{cancer}$ cells and in vivo mouse and patient-derived xenograft models [94]. In another work, the covalent inhibitor TED347 was developed to allosterically target the PPI between transcriptional enhanced associate domains (TEAD) and Yes1- associated protein (Yap), via reacting with a conserved cysteine residue inside the palmitate binding pocket of TEADs (Fig. 6) [90]. In patient-derived glioblastoma spheroids, TED-374-inhibited cell survival could also serve as a cancer probe in the Hippo signaling pathway. The case of covalent PPI inhibitor target TEAD Yap demonstrates that small molecule inhibitors could be more potent for largescale PPI interfaces with nucleophilic residues and tight pockets on binding site. Myeloid cell leukemia-1 (MCL-1) is one of most frequently amplified genes in cancer due to its role as a survival factor in different kinds of tumors $[95,96]$. The first covalent inhibitor targeting Mcl-1 was developed

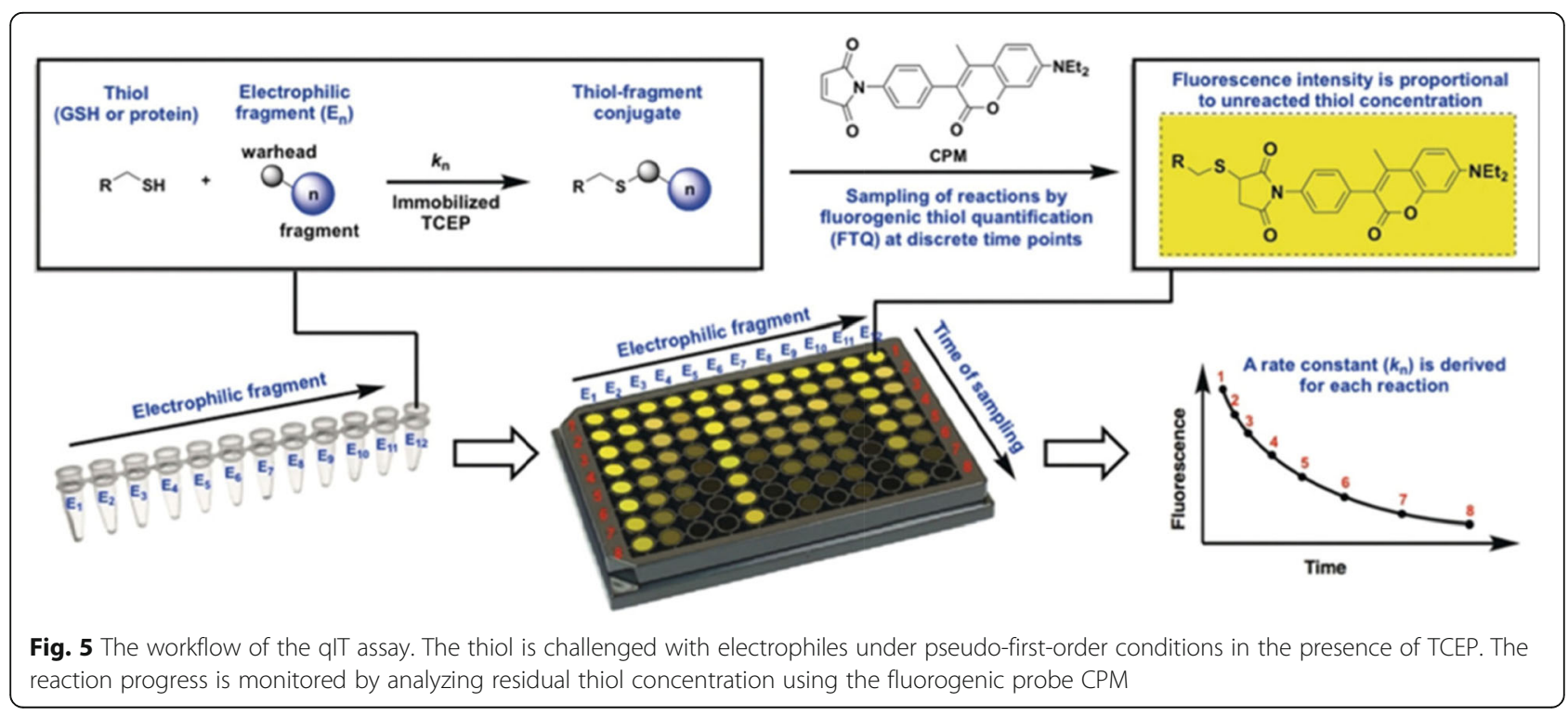


Table 1 Recent examples of successfully developed covalent PPI inhibitors

\begin{tabular}{|c|c|c|c|c|c|}
\hline Name & Type & Target & Prototypic cancer & Year & Reference \\
\hline Stattic & Peptide & HIF-1a/ARNT & Hepatocellular carcinoma & 2012 & [84] \\
\hline Aldehyde boronic acid & Small molecule warheads & Mcl-1/Bak & Multiple myeloma & 2016 & {$[47]$} \\
\hline RP-D & Peptide & Grb2/Sos1 & Breast cancer & 2017 & {$[85]$} \\
\hline Achiral oxoapomorphine & Small molecule inhibitors & P53/MDM2 & Prostate cancer & 2017 & [86] \\
\hline 1_AM & Small molecule inhibitors & $\mathrm{KRAS} / \mathrm{G} 12 \mathrm{C}$ & Lung cancer & 2017 & {$[87]$} \\
\hline $\mathrm{COHOOO}$ & Small molecule inhibitors & SUMO E1 & Colorectal cancer & 2018 & [88] \\
\hline Oridonin & Small molecule inhibitors & NLRP3/NEK7 & Breast cancer & 2018 & [89] \\
\hline TED-347 & Small molecule inhibitors & TEAD/Yap & Glioblastoma & 2019 & [90] \\
\hline Aryl-sulfonyl fluorides/aryl-fluoro sulfates & Small molecule warheads & XIAP/BIR3 & Ovarian cancer & 2019 & [61] \\
\hline cHBls & Small molecule inhibitors & Allergen/slgE & Colorectal cancer & 2019 & [91] \\
\hline
\end{tabular}

from an aryl boronic acid carbonyl warhead, which reacted with a noncatalytic lysine (Lys234) side chain of the protein. Notably, the inhibitor could activate apoptosis in an Mcl-1dependent multiple myeloma cell line [47]. Peptide-based covalent PPI inhibitors have also been reported. A reactive peptide derived from an antagonist was designed to target the Grb2-Sos1 PPI through binding to the SH3 domain of Grb2N. The dimeric peptide targeted the nucleophilic Cys32 site of Grb2N-SH3 to form a covalent thioether bond. Moreover, the inhibitor could target endogenous Grb2 and significantly inhibit mobility and viability in SK-BR-3 human breast cancer cells [95]. Although this peptide may not necessarily show features of drug-likeness, it could still be used as an irreversible probe of the Grb2-Sos1 interaction. THZ531, a CDK12-CDK13 covalent inhibitor, binds with CDK12-cyclin K via a cysteine residue that is located outside the kinase domain [97]. THZ531 inhibits hyperphosphorylated and elongating RNA polymerase II, while downregulating DNA damage response genes and associated transcription factor genes [97]. Furthermore, THZ531 induced cell death and apoptosis in Ewing sarcoma cancer cell lines. Developing covalent inhibitors of the CDK12-CDK13
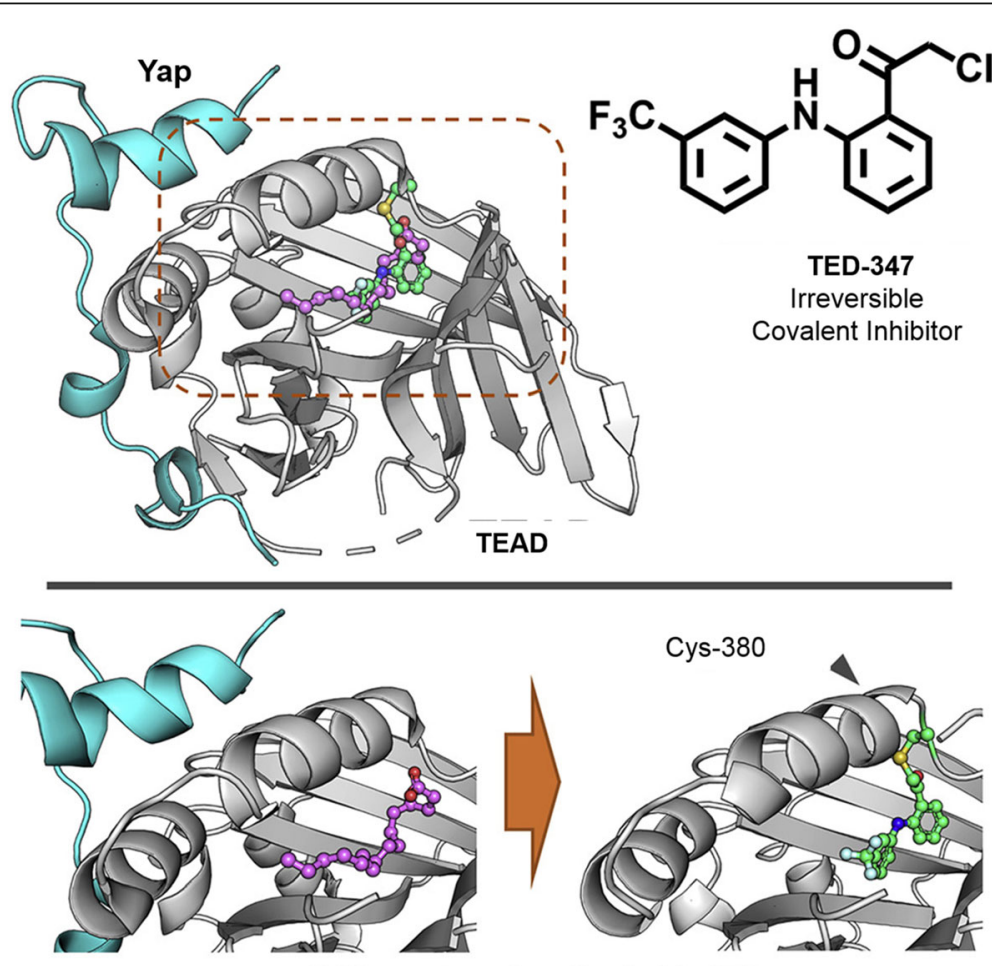

Allosteric Inhibition

Fig. 6 The covalent inhibitor TED-347 inhibits the TEAD-Yap PPI in allosteric formation by targeting a conserved cysteine within the palmitate pocket of TEAD 
PPI could help identify cancer subtypes that are susceptible to inhibition of this kinase activity [98]. Site-specific strategies can be used to design covalent PPI inhibitors for a wide range of residues. For example, boronic acid carbonyl warheads have been reported to modify the $\varepsilon$-amino group of lysine residues with high binding affinity [99]. This has been used to develop covalent inhibitors of Mcl-1 with biochemical and cellular activity [47]. These warhead covalent inhibitors avoid general cytotoxicity by specifically targeting Mcl-1 to activate caspases. Allosteric inhibitors have also been described that can target "switch II," an inducible pocket within RAS, but further optimization is required to advance them into clinical trials. Meanwhile, targeted covalent agents have shown potential for treating tumors caused by KRAS G12C [87].

\section{Conclusion remarks and perspectives Perspective and predicament for study PPI inhibitors in cancers}

For a long time, PPIs were regarded as "undruggable" targets, despite their importance in the regulation of signaling cascades in myriad diseases, including cancer [13]. With improvements in both chemical and biological technologies, the targeting of PPIs for cancer treatment is becoming an achievable reality. For example, in leukemia, the mixed lineage leukemia (MLL) protein interacts with menin to promote oncogenic activity. Therefore, developing small molecule inhibitors to directly disrupt the MLL-menin interaction is a potential strategy for leukemia treatment $[100,101]$. Furthermore, while many cancers are driven by aberrant kinase activity, it is thought that targeting the PPIs that regulate the activity of a specific kinase is a more viable approach to develop selective kinase inhibitors than targeting the conserved ATP binding site of kinases directly [4, 102, 103]. For instance, the heat shock protein (Hsp90)Cdc37 PPI promotes colorectal cancer. PPI inhibitors of Hsp90-Cdc37 could achieve selective inhibition of Hsp90 kinase without affecting other interactions that could lead to unnecessary toxicity [104]. Another disadvantage of targeting the active site of kinases is that those inhibitors are highly susceptible to resistance arising from mutations in the catalytic domain, such as drug resistance to imatinib in the case of chronic myeloid leukemia patients $[4,105]$. However, drawbacks of PPI inhibitors for anticancer therapy are that targeting PPIs has been found to be more difficult than targeting the active sites of enzymes or receptors. As highlighted above, fragment-based screening, computational analysis, and molecular inhibitor design are some of the techniques that have been used in PPI inhibitor development in drug discovery, including in the oncology field [106-110]. Such methods can accelerate the early phases of drug discovery by identifying PPIs as drug targets, followed by physicochemical and topographical characterization of their binding interfaces as well $[13,111,112]$. A number of (mostly non-covalent) PPI inhibitors have already been approved or entered clinical trials for the treatment of cancer (Table 2) [113]. However, non-covalent PPI inhibitors may have the ability to cause "off-target" effects due to binding to other molecules [114-116]. Thus, further research is needed to drive the effect of PPI inhibitors that are both potent and selective for their desired targets.

\section{Perspectives for the future development of covalent PPI inhibitors}

It is widely recognized that both covalent and non-covalent inhibitors have their respective advantages that can be exploited in different drug modalities, including PPI targeting. For example, non-covalent compound libraries are typically much larger than covalent inhibitors, which may increase the number of leads available for developing PPI inhibition. Non-covalent inhibitors are also thought to be less likely to lead to off-target effects compared to covalent inhibitors. For covalent inhibitors, one of their chief advantages is potentially more durable inhibition at the PPI site leading to improved pharmacology in vivo $[117,118]$. With covalent inhibition, the drug action time mainly depends on protein turnover time, rather than other pharmacokinetic properties [119]. This means that covalent PPI inhibitors can be highly potent at relatively low doses. The covalent approach can also be used to target shallow binding sites of receptors, enzymes, and PPI targets that are not conducive for non-covalent targeting. In addition, some analytical techniques such as click chemistry, activity probes, and mass spectrometry-based proteomics to evaluate binding activity and selectivity in vitro and in vivo are only available for covalent compounds [120-124]. The initial binding step (K1) and the subsequent chemical reaction step $\left(k_{\text {inact }}\right)$ are two important factors determining the selectivity of covalent inhibitors (Fig. 7) [37]. Having a high $\mathrm{Ki}$ is desirable for selectivity and provides sufficient time for the covalent reaction to happen. The rate constant of $k_{\text {inact }}$ should also be high to drive the reaction to completion during the lifetime of the non-covalent complex. These techniques that have been mentioned above allow for the determining of covalent binding occupancy and biological efficiency in PPIs.

It should be noted that while covalent inhibitors are excellent candidates for disrupting PPIs, they may not be ideal choices for other targets $[125,126]$. For example, G-protein-coupled receptors (GPCRs) are influenced by trafficking progress and then internalized in the cell membrane and recycled or degraded. Covalent molecules may not be able to effectively target GPCRs during this turnover process [127]. Moreover, the chief advantage of covalent drugs, i.e., strong binding, may not be desirable for all targets or for all cases. Furthermore, the targets of infectious diseases usually have high replication rates, while covalent inhibitors tend to have 
Table 2 Examples of small-molecule development candidates identified against PPIs in cancer treatment

\begin{tabular}{|c|c|c|}
\hline Compound name & Therapeutic area & Highest phase reached \\
\hline \multicolumn{3}{|l|}{ BCL-2 family } \\
\hline Obatoclax (CEP-41601, GX015-070) & Extensive-stage small cell lung cancer & Phase III (discontinued) \\
\hline Navitoclax (ABT-263) & Chronic lymphocytic leukemia/prostate cancer & Phase II (completed) \\
\hline Venetoclax (ABT-199) & Leukemia/acute myeloid leukemia & Phase I \\
\hline \multicolumn{3}{|l|}{ MDM2-p53 pathway } \\
\hline Idasanutlin (RO5503781) & Leukemia/acute myeloid leukemia & Phase III \\
\hline AMG232 & Metastatic melanoma & Phase $\mid / I I$ \\
\hline CGM097 & Solid tumor with wild-type p53 & Phase I \\
\hline DS-3032b & Advanced solid tumors/lymphomas & Phase I \\
\hline ALRN-6924 & $\begin{array}{l}\text { Acute myeloid leukemia /advanced } \\
\text { myelodysplastic syndrome }\end{array}$ & Phase I \\
\hline MK-8242 & Advanced solid tumors & Phase I \\
\hline JNJ-26854165 & Advanced stage or refractory solid tumors & Phase I (completed) \\
\hline RG-7112 (RO5045337) & Hematologic neoplasms & Phase I (completed) \\
\hline SAR-405838 & Malignant neoplasms & Phase I \\
\hline \multicolumn{3}{|l|}{ IAP pathway } \\
\hline AT-406 (Debio-1143) & Solid tumor & Phase II \\
\hline LCL-161 & Breast cancer & Phase II \\
\hline Birinapant (TL32711) & Advanced or metastatic solid tumors & Phase $1 / \|$ \\
\hline ASTX-660 & Advanced solid tumors and lymphomas & Phase $\mid / / I$ \\
\hline AEG40826 (HGS1029) & Advanced solid tumors & Phase I \\
\hline CUDC-427 (GDC-0917) & Lymphoma & Phase I \\
\hline GDC-0152 (RG-7419) & Advanced or metastatic malignancies & Phase I (discontinued) \\
\hline GSK525762 & Breast cancer & Phase $|/| I$ \\
\hline CPI-0610 & Multiple myeloma & Phase I \\
\hline TEN-010 & Acute myeloid leukemia & Phase I \\
\hline OTX015 (MK-8628) & Hematologic malignancies & Phase I (completed) \\
\hline
\end{tabular}

long residence times making them less effective in this area [128].

Although there are many potential advantages (e.g., long targeting action and high potency) of covalent PPI inhibitors, their disadvantages should not be neglected. Covalent
PPI inhibitors can form chemically reactive metabolites when they bind to the target protein [129], which can lead to severe side effects [130]. For example, the oxidation of drugs such as furosemide, isoniazid, acetaminophen, halothane, and model hepatotoxins via cytochrome P-450 can

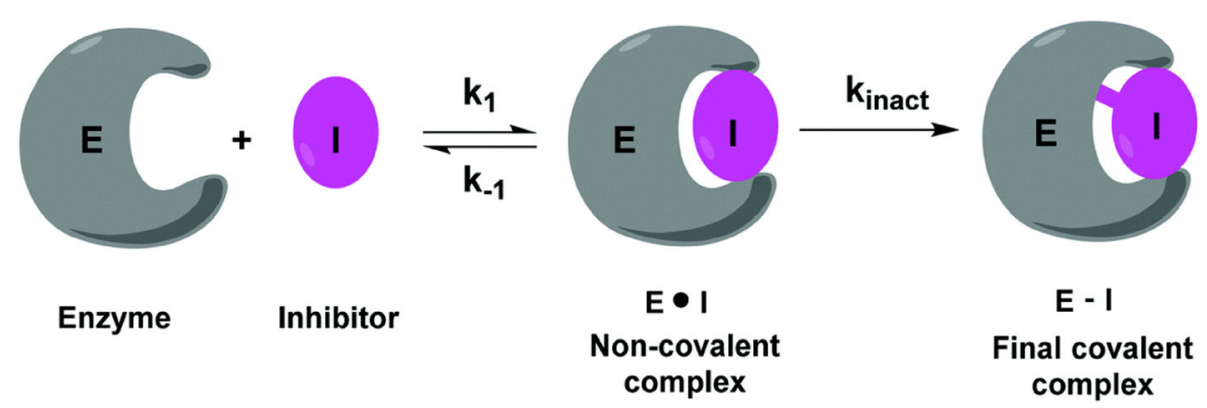

Fig. 7 The equations for the target-specific action of covalent inhibitors. E: enzyme target, l: inhibitor, $k_{\text {inact }}$ : rate of inactivation of the target, $k 2$ : rate of the subsequent bond-forming reaction, Kl: inhibition constant 
Table 3 The advantages and disadvantages of covalent and noncovalent PPI inhibitors

\begin{tabular}{lll}
\hline & Advantages & Disadvantages \\
\hline $\begin{array}{ll}\text { Covalent PPI } \\
\text { inhibitors }\end{array}$ & Longer duration of & Off-target toxicity \\
& action & Potential immunogenicity \\
& Lower prolonged & of the resulting target \\
& systemic exposure & adducts \\
& Higher potency and & \\
& selectivity & \\
& Higher biochemical & \\
& efficiency & \\
& Less sensitive to & \\
& pharmacokinetic & \\
& parameters & \\
& Computational & \\
& prediction of reversible & \\
& covalent binding & \\
& Lower risk of drug & \\
& resistance & \\
Non-covalent & Larger non-covalent & Not very selective \\
PPI inhibitors & compound libraries & Usually weak reactivity \\
& Long dissociated & Limit to non-covalent \\
& half-lives & binding affinity \\
& Less off-target toxicity & Not very potent \\
\hline
\end{tabular}

lead to hepatotoxic effects in animals and humans [131, 132]. Possible toxicity arising from protein haptenization is also a potential risk of covalent PPI inhibitors [133, 134]. In some clinical trials, immunogenicity was observed several weeks or months after treatment with covalent drugs [135, 136]. Additionally, some covalent inhibitors with reactive functional groups tend to be unattractive for drug discovery because of the poor pharmacokinetic values, especially high clearance [137]. Thus, it is necessary to develop strategies to evaluate the likelihood of covalent inhibitors undergoing metabolism in order to prevent drug toxicity as much as possible at the early stage of covalent PPI inhibitor development [138]. Several approaches have recently been reported in order to minimize the risk of side effects of covalent PPI agents. For instance, some covalent bifunctional blockers are designed with deliberately weak reactivity in order to increase stability and to decrease toxicity. In some cases, covalent inhibitors can be designed to be cleared rapidly after blocking the PPI, which could reduce non-mechanismbased toxicity $[37,139]$. Overcoming toxicity is one of the main bottlenecks preventing covalent inhibitors from entering the market [140]. A summary of the advantages and disadvantages of covalent and non-covalent PPI inhibitors is presented in Table 3 .

Additionally, precise mechanisms by which covalent inhibitors form covalent bonds with their target proteins to exert pharmacological and toxicological effects are still unclear. Therefore, shedding light on the potential mechanisms of pharmacology and toxicology of covalent PPI inhibitors is an important directive to facilitate drug development. Moreover, frameworks to evaluate the reactivity profiles, efficiency, selectivity, and toxicity of covalent inhibitors need to be established. Overcoming these challenges will provide renewed impetus for scientists to explore novel covalent inhibitors targeting PPI for various human diseases. In conclusion, we believe that covalent PPI inhibitors have a promising future and more of such therapeutic agents will be developed in the coming years.

\section{Abbreviations \\ ABPP: Activity-based protein profiling; ABPs: Activity-based probes; AVPF: Ala- Val-Pro-Phe; FDA: Food and Drug Administration; FTQ: Fluorogenic thiol quantification; GPCRs: G-protein-coupled receptors; Hsp90: Heat shock protein 90; HTS: High-throughput screening; isoTOP-ABPP: Isotopic tandem orthogonal proteolysis activity-based protein profiling; MCL-1: Myeloid cell leukemia-1; MD: Molecular dynamics; PPIs: Protein-protein interactions; qIT: Quantitative irreversible tethering; QSAR: Quantitative structure activity relationships; SMAC: Second mitochondria-derived activator of caspase: SUMO: Small ubiquitin-related modifier; TEAD: Transcriptional enhanced associate domains; XIAP: X-linked inhibitor of apoptosis protein; Yap: Yes1- associated protein}

\section{Acknowledgements}

Not applicable.

\section{Authors' contributions}

The authors contributed to the data preparation and drafted and revised the manuscript. All authors read and approved the final manuscript.

\section{Funding}

This research is supported by Hong Kong Baptist University (FRG2/17-18/ 003), the Health and Medical Research Fund (HMRF/14150561), the National Natural Science Foundation of China $(21575121,21775131)$, the Hong Kong

Baptist University Century Club Sponsorship Scheme 2019, the Interdisciplinary Research Matching Scheme (RC-IRMS/16-17/03), Interdisciplinary Research Clusters Matching Scheme (RC-IRCs/17-18/03), Collaborative Research Fund (C5026-16G), SKLEBA and HKBU Strategic Development Fund (SKLP_1920_P02), the Science and Technology Development Fund, Macau SAR (0072/2018/A2), and the University of Macau (MYRG2019-00002-ICMS and MYRG2018-00187-ICMS).

\section{Availability of data and materials}

Not applicable.

Ethics approval and consent to participate Not applicable.

\section{Consent for publication}

Not applicable.

\section{Competing interests}

The authors declare that they have no competing interests.

\section{Author details}

'Institute of Chinese Medical Sciences, State Key Laboratory of Quality Research in Chinese Medicine, University of Macau, Macao, SAR, China. ${ }^{2}$ Department of Chemistry, Hong Kong Baptist University, Kowloon 999077, Hong Kong, China. ${ }^{3}$ Institute of Medical Research, Northwestern Polytechnical University, Xi'an 710072, China.

Received: 18 December 2019 Accepted: 20 February 2020 Published online: 30 March 2020

\section{References}

1. Mabonga L, Kappo AP. Protein-protein interaction modulators: advances, successes and remaining challenges. Biophys Rev. 2019;11(4):559-81.

2. Koh GC, Porras P, Aranda B, Hermjakob H, Orchard SE. Analyzing proteinprotein interaction networks. J Proteome Res. 2012;11(4):2014-31.

3. Gonzalez MW, Kann MG. Chapter 4: Protein interactions and disease. PLoS Comput Biol. 2012;8(12):e1002819. 
4. Cierpicki T, Grembecka J. Targeting protein-protein interactions in hematologic malignancies: still a challenge or a great opportunity for future therapies? Immunol Rev. 2015;263(1):279-301.

5. Zhong M, Lee GM, Sijbesma E, Ottmann C, Arkin MR. Modulating proteinprotein interaction networks in protein homeostasis. Curr Opin Chem Biol. 2019:50:55-65

6. Titeca K, Lemmens I, Tavernier J, Eyckerman S. Discovering cellular proteinprotein interactions: technological strategies and opportunities. Mass Spectrom Rev. 2019;38(1):79-111.

7. Pattin KA, Moore JH. Role for protein-protein interaction databases in human genetics. Expert Rev Proteomic. 2009;6(6):647-59.

8. Hu G, Wu Z, Uversky V, Kurgan L. Functional analysis of human hub proteins and their interactors involved in the intrinsic disorder-enriched interactions. Int J Mol Sci. 2017;18(12):2761.

9. Milo R. What is the total number of protein molecules per cell volume? A call to rethink some published values. Bioessays. 2013;35(12):1050-5.

10. Kuzmanov U, Emili A. Protein-protein interaction networks: probing disease mechanisms using model systems. Genome Med. 2013;5(4):37.

11. Ori A, Iskar M, Buczak K, Kastritis P, Parca L, Andrés-Pons A, Singer S, Bork P, Beck M. Spatiotemporal variation of mammalian protein complex stoichiometries. Genome Biol. 2016:17(1):47.

12. Yang GJ, Wang W, Mok SWF, Wu C, Law BYK, Miao XM, et al. Selective inhibition of lysine-specific demethylase 5A (KDM5A) using a rhodium (III) complex for triple-negative breast cancer therapy. Angew Chem Int Ed. 2018;57(40):13091-5.

13. Ivanov AA, Khuri FR, Fu H. Targeting protein-protein interactions as an anticancer strategy. Trends Pharmacol Sci. 2013;34(7):393-400.

14. Hanahan D, Weinberg RA. Hallmarks of cancer: the next generation. Cell. 2011;144(5):646-74.

15. Garner $A L$, Janda KD. Protein-protein interactions and cancer: targeting the central dogma. Curr Top Med Chem. 2011;11(3):258-80.

16. Miao S, Qiu T, Zhao $Y$, Wang H, Sun X, Wang $Y$, Xuan $Y$, Qin $Y$, Jiao WJT. Overexpression of S100A13 protein is associated with tumor angiogenesis and poor survival in patients with early-stage non-small cell lung cancer. Thoracic Cancer. 2018;9(9):1136-44.

17. Han H, Zhan Z, Xu J, Song ZJO. Therapy: TMEFF2 inhibits pancreatic cancer cells proliferation, migration, and invasion by suppressing phosphorylation of the MAPK signaling pathway. OncoTargets Ther. 2019;12:11371-82.

18. Huang Y, Liu N, Liu J, et al. Mutant p53 drives cancer chemotherapy resistance due to loss of function on activating transcription of PUMA. Cell Cycle. 2019;18(24):3442-55.

19. Ryan DP, Matthews JM. Protein-protein interactions in human disease. Curr Opin Struct Biol. 2005;15(4):441-6.

20. Bowler EH, Wang Z, Ewing RM. How do oncoprotein mutations rewire protein-protein interaction networks? 2015;12(5):449-55.

21. Kar G, Gursoy A, Keskin O. Human cancer protein-protein interaction network: a structural perspective. PLoS Comput Biol. 2009:5(12):e1000601.

22. Nero TL, Morton CJ, Holien JK, et al. Oncogenic protein interfaces: small molecules, big challenges. Nat Rev Cancer. 2014;14(4):248-62.

23. Selkoe DJ, Hardy J. The amyloid hypothesis of Alzheimer's disease at 25 years. EMBO Mol Med. 2016;8(6):595-608.

24. Arkin MR, Tang Y, Wells JA. Small-molecule inhibitors of protein-protein interactions: progressing toward the reality. Chem Biol. 2014;21(9):1102-14.

25. Basse M, Betzi S, Morelli X, et al. 2P2ldb v2: update of a structural database dedicated to orthosteric modulation of protein-protein interactions. Database. 2016; 2016.

26. Cossar PJ, Lewis PJ, McCluskey A. Protein-protein interactions as antibiotic targets: a medicinal chemistry perspective. Med Res Rev. 2018:1-26.

27. Raj M, Bullock BN, Arora PS. Plucking the high hanging fruit: a systematic approach for targeting protein-protein interactions. Bioorg Med Chem. 2013;21(14):4051-7.

28. London N, Raveh B, Movshovitz, Attias D, et al. Can self-inhibitory peptides be derived from the interfaces of globular protein-protein interactions? Proteins. 2010;78(15):3140-9.

29. He S, Senter TJ, Pollock J, Han C, Upadhyay SK, Purohit T, et al. High-affinity smallmolecule inhibitors of the menin-mixed lineage leukemia (MLL) interaction closely mimic a natural protein-protein interaction. J Med Chem. 2014;57(4):1543-56.

30. Bourgeas R, Basse M-J, Morelli X, Roche PJP. Atomic analysis of proteinprotein interfaces with known inhibitors: the 2P2I database. 2010;5(3):e9598.

31. Basse MJ, Betzi S, Bourgeas R, Bouzidi S, Chetrit B, Hamon V, et al. 2P2ldb: a structural database dedicated to orthosteric modulation of protein-protein interactions. Nucleic Acids Res. 2012;41(D1):D824-7.
32. Higueruelo AP, Jubb H, Blundell TL. TIMBAL v2. Update of a database holding small molecules modulating protein-protein interactions. Database. 2013;2013.

33. Labbé CM, Laconde G, Kuenemann MA, et al. iPPI-DB: a manually curated and interactive database of small non-peptide inhibitors of protein-protein interactions. Drug Discov Today. 2013;18(19-20):958-68.

34. Choi S, Choi KY. Screening-based approaches to identify small molecules that inhibit protein-protein interactions. Expert Opin Drug Discovery. 2017; 12(3):293-303.

35. Paul SM, Mytelka DS, Dunwiddie CT, Persinger CC, Munos BH, Lindborg SR, et al. How to improve R\&D productivity: the pharmaceutical industry's grand challenge. Nat Rev Drug Discov. 2010;9(3):203.

36. Jin L, Wang W, Fang G. Targeting protein-protein interaction by small molecules. Annu Rev Pharmacol Toxicol. 2014;54:435-56.

37. Singh J, Petter RC, Baillie TA, Whitty A. The resurgence of covalent drugs. Nat Rev Drug Discov. 2011;10(4):307-17.

38. Zhong HJ, Lu L, Leung KH, Wong CC, Peng C, Yan SC, et al. An iridium (III)based irreversible protein-protein interaction inhibitor of BRD4 as a potent anticancer agent. Chem Sci. 2015;6(10):5400-8.

39. Bjij I, Ramharack P, Khan S, Cherqaoui D, Soliman MEJM. Tracing potential covalent inhibitors of an E3 ubiquitin ligase through target-focused modelling. Molecules. 2019;24(17):3125.

40. Lonsdale R, Ward RA. Structure-based design of targeted covalent inhibitors. Chem Soc Rev. 2018;47(11):3816-30.

41. Walter AO, Sjin RTT, Haringsma HJ, Ohashi K, Sun J, Lee K, et al. Discovery of a mutant-selective covalent inhibitor of EGFR that overcomes T790Mmediated resistance in NSCLC. Cancer Discov. 2013;3(12):1404-15.

42. Rudolph J, Stokoe D. Selective inhibition of mutant Ras protein through covalent binding. Angew Chem Int Ed. 2014;53(15):3777-9.

43. Basu D, Richters A, Rauh D. Structure-based design and synthesis of covalent-reversible inhibitors to overcome drug resistance in EGFR. Bioorg Med Chem. 2015;23(12):2767-80.

44. Finlay MRV, Anderton M, Ashton S, Ballard P, Bethel PA, Box MR, et al. Discovery of a potent and selective EGFR inhibitor (AZD9291) of both sensitizing and T790M resistance mutations that spares the wild type form of the receptor. ACS Publications. 2014:8249-67.

45. Barf T, Kaptein AJ. Irreversible protein kinase inhibitors: balancing the benefits and risks. J Med Chem. 2012;55(14):6243-62.

46. Choi S, Connelly S, Reixach N, Wilson IA, Kelly JW. Chemoselective small molecules that covalently modify one lysine in a non-enzyme protein in plasma. Nat Chem Biol. 2010;6(2):133

47. Akçay G, Belmonte MA, Aquila B, Chuaqui C, Hird AW, Lamb ML, et al. Inhibition of Mcl-1 through covalent modification of a noncatalytic lysine side chain. Nat Chem Biol. 2016;12(11):931.

48. Tsou LK, Cheng Y, Cheng YC. Therapeutic development in targeting protein-protein interactions with synthetic topological mimetics. Curr Opin Pharmacol. 2012:12(4):403-7.

49. Wu X, Wang L, Han Y, Regan N, Li PK, Villalona MA, et al. Creating diverse target-binding surfaces on FKBP12: synthesis and evaluation of a rapamycin analogue library. ACS Comb Sci. 2011;13(5):486-95.

50. Wu C, Yao M, Li W, Cui B, Dong H, Ren Y, Yang C, Gan CJM. Simultaneous determination and pharmacokinetics study of six triterpenes in rat plasma by UHPLC-MS/MS after oral administration of sanguisorba officinalis $L$ extract. Molecules. 2018;23(11):2980.

51. Liu L, Leung $K$, Chan DS, Wang Y, Ma D. Leung $C H$, disease: Identification of a natural product-like STAT3 dimerization inhibitor by structure-based virtua screening. Cell Death Dis. 2014;5(6):e1293.

52. Jubb H, Higueruelo AP, Winter A, Blundell TL. Structural biology and drug discovery for protein-protein interactions. Trends Pharmacol Sci. 2012;33(5):241-8.

53. Backus KM, Correia BE, Lum KM, Forli S, Horning BD, González-Páez GE, Chatterjee S, Lanning BR, Teijaro JR, Olson A. Proteome-wide covalent ligand discovery in native biological systems. Nature. 2016;534(7608):570.

54. London N, Miller RM, Krishnan S, Uchida K, Irwin JJ, Eidam O, et al. Covalent docking of large libraries for the discovery of chemical probes. Nat Chem Biol. 2014;10(12):1066.

55. Zhang Y, Zhang D, Tian H, Jiao Y, Shi Z, Ran T, et al. Identification of covalent binding sites targeting cysteines based on computational approaches. J Med Chem. 2016;13(9):3106-18.

56. Zhao Z, Liu Q, Bliven S, Xie L. Bourne PEJJomc. Determining cysteines available for covalent inhibition across the human kinome. J Med Chem. 2017;60(7):2879-89. 
57. Wu S, Luo H, Wang H, Zhao W, Hu Q, Yang YJB. The first comprehensive database for proteins with targetable cysteine and their covalent inhibitors. Biochem Biophys Res Commun. 2016;478(3):1268-73.

58. Guo Z, Li B, Cheng L-T, Zhou S, McCammon JA. Che J Identification of protein-ligand binding sites by the level-set variational implicit-solvent approach. J Chem Theory Comput. 2015;11(2):753-65.

59. Cai Q, Sun H, Peng Y, Lu J, Nikolovska-Coleska Z, McEachern D, et al. A potent and orally active antagonist (SM-406/AT-406) of multiple inhibitor of apoptosis proteins (IAPs) in clinical development for cancer treatment. J Med Chem. 2011:54(8):2714-26.

60. Liu Z, Sun C, Olejniczak ET, Meadows RP, Betz SF, Oost T, et al. Structural basis for binding of Smac/DIABLO to the XIAP BIR3 domain. Nature. 2000; 408(6815):1004.

61. Gambini L, Baggio C, Udompholkul P, Jossart J, Salem AF, et al. Covalent inhibitors of protein-protein interactions targeting lysine, tyrosine, or histidine residues. J Med Chem. 2019;62(11):5616-27.

62. Oost TK, Sun C, Armstrong RC, Al-Assaad A-S, Betz SF, Deckwerth TL, et al. Discovery of potent antagonists of the antiapoptotic protein XIAP for the treatment of cancer. J Med Chem. 2004:47(18):4417-26.

63. Chen $\mathrm{X}$, Wong YK, Wang J, Zhang J, Lee YM, Shen HM, et al. Target identification with quantitative activity-based protein profiling (ABPP). Proteomics. 2017;17(3-4):1600212.

64. Maurais AJ, Weerapana E. Reactive-cysteine profiling for drug discovery. Curr Opin Chem Biol. 2019;50:29-36.

65. Lanning BR, Whitby LR, Dix MM, Douhan J, Gilbert AM, Hett EC, et al. Niessen SJNcb: A road map to evaluate the proteome-wide selectivity of covalent kinase inhibitors. Nat Chem Biol. 2014;10(9):760.

66. Weerapana E, Wang C, Simon GM, Richter F, Khare S, Dillon MB, et al. Quantitative reactivity profiling predicts functional cysteines in proteomes. Nature. 2010;468(7325):790.

67. Shannon DA, Banerjee R, Webster ER, Bak DW, Wang C, Weerapana E, Investigating the proteome reactivity and selectivity of aryl halides. J Am Chem Soc 2014;136(9):3330-3.

68. Ward CC, Kleinman JI, Nomura DK. NHS-esters as versatile reactivity-based probes for mapping proteome-wide ligandable hotspots. ACS Chem Biol. 2017:12(6):1478-83.

69. Louie SM, Grossman EA, Crawford LA, Ding L, Camarda R, Huffman TR, et al. GSTP1 is a driver of triple-negative breast cancer cell metabolism and pathogenicity. Cell Chem Biol. 2016;23(5):567-78.

70. Anderson KE, To M, Olzmann JA, Nomura DK. Chemoproteomics-enabled covalent ligand screening reveals a thioredoxin-caspase 3 interaction disruptor that impairs breast cancer pathogenicity. ACS Chem Biol. 2017: 12(10):2522-8

71. Lu X-G, Wang Z, Cui Y, Jin Z. Computational thermodynamics, computational kinetics, and materials design. Chin Sci Bull. 2014;59(15): 1662-71.

72. Honarparvar B, Govender T, Maguire GE, Soliman ME. Kruger HGJCr. Integrated approach to structure-based enzymatic drug design: molecular modeling, spectroscopy, and experimental bioactivity. Chem Rev. 2013; 114(1):493-537.

73. Scarpino A, Ferenczy GG, Keserü GM. Comparative evaluation of covalent docking tools. J Chem Inf Model. 2018;58(7):1441-58.

74. Kumalo HM, Bhakat S, Soliman ME. Theory and applications of covalent docking in drug discovery: merits and pitfalls. Molecules. 2015;20(2):1984-2000.

75. Ouyang X, Zhou S, Su CTT, Ge Z, Li R, Kwoh CK. CovalentDock: automated covalent docking with parameterized covalent linkage energy estimation and molecular geometry constraints. J Comput Chem. 2013;34(4):326-36.

76. Cosconati S, Forli S, Pernyman AL, Harris R, Goodsell DS, Olson A. Virtual screening with AutoDock: theory and practice. Expert Opin Drug Discovery. 2010;5(6):597-607.

77. Toledo Warshaviak D, Golan G, Borrelli KW, Zhu K, Kalid O. Structure-based virtual screening approach for discovery of covalently bound ligands. J Chem Inf Model. 2014:54(7):1941-50.

78. Nguyen VS, Loh XY, Wijaya H, Wang J, Lin Q, Lam Y, et al. Specificity and inhibitory mechanism of andrographolide and its analogues as antiasthma agents on NF-KB p50. J Nat Prod. 2015;78(2):208-17.

79. Miller RM, Paavilainen VO, Krishnan S, Serafimova IM, Taunton J. Electrophilic fragment-based design of reversible covalent kinase inhibitors. J Am Chem Soc. 2013;135(14):5298-301

80. Ostrem JM, Peters U, Sos ML, Wells JA, Shokat KMJN. K-Ras (G12C) inhibitors allosterically control GTP affinity and effector interactions. Nature. 2013; 503(7477):548.
81. Swinney DC, Anthony J. How were new medicines discovered? Nat Rev Drug Discov 2011;0(7):507.

82. Craven GB, Affron DP, Allen CE, Matthies S, Greener JG, Morgan RM, et al. High-throughput kinetic analysis for target-directed covalent ligand discovery. Angew Chem Int Ed. 2018;57(19):5257-61.

83. Chen $X$, Zhou $Y$, Peng $X$, Yoon JJCSR. Fluorescent and colorimetric probes for detection of thiols. Chem Soc Rev. 2010;39(6):2120-35.

84. Cardoso R, Love R, Nilsson CL, Bergqvist S, Nowlin D, Yan J, et al. Identification of Cys255 in HIF-1a as a novel site for development of covalent inhibitors of HIF-1 1 /ARNT PasB domain protein-protein interaction. Protein Sci. 2012;21(12):1885-96.

85. Yu Y, Nie Y, Feng Q, Qu J, Wang R, Bian L, et al. Targeted covalent inhibition of Grb2-Sos1 interaction through proximity-induced conjugation in breast cancer cells. Mol Pharm. 2017;14(5):1548-57.

86. Ishiba H, Noguchi T, Shu K, Ohno H, Honda K, Kondoh Y, et al. Investigation of the inhibitory mechanism of apomorphine against MDM2-p53 interaction. Bioorg Med Chem Lett. 2017:27(11):2571-4.

87. Zeng M, Lu J, Li L, Feru F, Quan C, Gero TW, et al. Potent and selective covalent quinazoline inhibitors of KRAS G12C. Cell Chem Biol. 2017;24(8): 1005-1016e1003.

88. Lv Z, Yuan L, Atkison JH, Williams KM, Sessions EH, Divlianska DB, et al. Molecular mechanism of a covalent allosteric inhibitor of SUMO E1 activating enzyme. Nat Commun. 2018;9(1):5145.

89. He H, Jiang H, Chen Y, Ye J, Wang A, Wang C, et al. Oridonin is a covalent NLRP3 inhibitor with strong anti-inflammasome activity. Nat Commun. 2018; 9(1):2550

90. Bum-Erdene K, Zhou D, Gonzalez-Gutierrez G, Ghozayel MK, Si Y, Xu D, et al. Small-molecule covalent modification of conserved cysteine leads to allosteric inhibition of the TEAD Yap protein-protein interaction. Cell Chem Biol. 2019:26(3):378-389e313.

91. Deak PE, Kim B, Abdul Qayum A, Shin J, Vitalpur G, Kloepfer KM, et al. Designer covalent heterobivalent inhibitors prevent lgE-dependent responses to peanut allergen. Proc Natl Acad Sci U S A. 2019;116(18):896674.

92. Charoenpattarapreeda J, Tan YS, legre J, Walsh SJ, Fowler E, Eapen RS, et al. Targeted covalent inhibitors of MDM2 using electrophile-bearing stapled peptides. Chem Commun (Camb). 2019;55(55):7914-7.

93. Bakail M, Ochsenbein F. Targeting protein-protein interactions, a wide open field for drug design. Comptes Rendus Chimie. 2016;19(1-2):19-27.

94. Li Y-J, Du L, Wang J, Vega R, Lee TD, Miao Y, et al. Allosteric inhibition of ubiquitin-like modifications by a class of inhibitor of SUMO-activating enzyme. Cell Chem Biol. 2019:26(2):278-88.e276.

95. Czabotar PE, Lessene G, Strasser A, Adams JM. Control of apoptosis by the $\mathrm{BCL}-2$ protein family: implications for physiology and therapy. Nat Rev Mo Cell Biol. 2014;15(1):49.

96. Wei G, Margolin AA, Haery L, Brown E, Cucolo L, Julian B, et al. Chemical genomics identifies small-molecule MCL1 repressors and BCL-XL as a predictor of MCL1 dependency. Cancer Cell. 2012;21(4):547-62.

97. Zhang T, Kwiatkowski N, Olson CM, Dixon-Clarke SE, Abraham BJ, Greifenberg AK, et al. Covalent targeting of remote cysteine residues to develop CDK12 and CDK13 inhibitors. Nat Chem Biol. 2016;12(10):876-84.

98. Iniguez AB, Stolte B, Wang EJ, Conway AS, Alexe G, Dharia NV, et al. EWS/FLI confers tumor cell synthetic lethality to CDK12 inhibition in Ewing sarcoma. Cancer Cell. 2018;33(2):202-216.e206.

99. Cal PM, Vicente JB, Pires E, Coelho AV, Veiros LF, Cordeiro C, et al. Iminoboronates: a new strategy for reversible protein modification. J Am Chem Soc. 2012;134(24):10299-305.

100. Aguilar A, Zheng K, Xu T, Xu S, Huang L, Fernandez-Salas E, et al. Structure-based discovery of M-89 as a highly potent inhibitor of the menin-mixed lineage leukemia (Menin-MLL) protein-protein interaction. J Med Chem. 2019;62(13):6015-34

101. Zhong HJ, Lee BR, Boyle JW, Wang W, Ma D-L, Chan PWH, et al. Structurebased screening and optimization of cytisine derivatives as inhibitors of the menin-MLL interaction. Chem Commun. 2016;52(34):5788-91.

102. Tan HY, Wang N, Lam W, Guo W, Feng Y, Cheng YC. Targeting tumour microenvironment by tyrosine kinase inhibitor. Mol Cancer. 2018;17(1):43.

103. Yj M, Liang Y, Hb H, Zhao Hy WCP, Wang F, et al. Apatinib (YN968D1) reverses multidrug resistance by inhibiting the efflux function of multiple ATP-binding cassette transporters. Cancer Res. 2010;70(20):7981-91.

104. Wang L, Zhang L, Li L, Jiang J, Zheng Z, Shang J, et al. Small-molecule inhibitor targeting the Hsp90-Cdc37 protein-protein interaction in colorectal cancer. Sci Adv. 2019;5(9):eaax2277. 
105. Chen ZS, Tiwari AK. Multidrug resistance proteins (MRPS/ABCCs) in cancer chemotherapy and genetic diseases. FEBS J. 2011;278(18):3226-45.

106. Valkov E, Sharpe T, Marsh M, Greive S, Hyvönen M. Targeting proteinprotein interactions and fragment-based drug discovery. Fragment-Based Drug Discovery and X-Ray Crystallography. 2011:145-79.

107. MC Meireles L, Mustata G. Discovery of modulators of protein-protein interactions: current approaches and limitations. Curr Top Med Chem. 2011; 11(3):248-57.

108. Winter A, Higueruelo AP, Marsh M, Sigurdardottir A, Pitt WR, Blundell TL. Biophysical and computational fragment-based approaches to targeting protein-protein interactions: applications in structure-guided drug discovery. Q Rev Biophys. 2012;45(4):383-426.

109. Lin L, Hutzen B, Li P-K, Ball S, Zuo M, DeAngelis S, et al. A novel small molecule, LLL12, inhibits STAT3 phosphorylation and activities and exhibits potent growth-suppressive activity in human cancer cells. Neoplasia. 2010; 12(1):39-IN35.

110. Zhong HJ, Liu LJ, Chong C-M, Lu L, Wang M, Chan DS-H, et al. Discovery of a natural product-like iNOS inhibitor by molecular docking with potential neuroprotective effects in vivo. PLoS One. 2014;9(4):e92905.

111. Tejo C, See YFA, Mathiew M, Chan PW. Synthesis of 1, 4-amino alcohols by Grignard reagent addition to THF and N-tosyliminobenzyliodinane. Org Biomol Chem. 2016;14(3):844-8.

112. Liu LJ, Wang W, Huang SY, Hong Y, Li G, Lin S, et al. Inhibition of the Ras/ Raf interaction and repression of renal cancer xenografts in vivo by an enantiomeric iridium (III) metal-based compound. Chem Sci. 2017;8(7):475663.

113. Scott DE, Bayly AR, Abell C, Skidmore J. Small molecules, big targets: drug discovery faces the protein-protein interaction challenge. Nat Rev Drug Discov. 2016;15(8):533-50.

114. Morelli X, Bourgeas R, Roche P. Chemical and structural lessons from recent successes in protein-protein interaction inhibition (2P2I). Curr Opin Chem Biol. 2011;15(4):475-81.

115. Wendt MD. Protein-protein interactions as drug targets. In: Protein-Protein Interactions Springer. 2012:1-55.

116. Smith RD, Lu J, Carlson HA. Are there physicochemical differences between allosteric and competitive ligands? PLoS Comput Biol. 2017;13(11):e1005813.

117. Long MJC, Aye Y. Privileged electrophile sensors: a resource for covalent drug development. Cell Chem Biol. 2017;24(7):787-800.

118. Wacker D, Stevens RC. Roth BL How ligands illuminate GPCR molecular pharmacology. Cell. 2017;170(3):414-27.

119. Joseph-McCarthy D, Campbell AJ, Kern G. Moustakas D, modeling: Fragment-based lead discovery and design. J Chem Inf Model. 2014;54(3): 693-704.

120. Moellering RE, Cravatt BF. How chemoproteomics can enable drug discovery and development. Chem Biol. 2012;19(1):11-22.

121. Li N, Overkleeft HS, Florea BI. Activity-based protein profiling: an enabling technology in chemical biology research. Curr Opin Chem Biol. 2012;16(1-2): 227-33.

122. Sanman LE, Bogyo M. Activity-based profiling of proteases. Annu Rev Biochem. 2014;83:249-73.

123. Schirle M, Bantscheff M. Kuster B Mass spectrometry-based proteomics in preclinical drug discovery. Anal Chem. 2012;19(1):72-84.

124. Law FC, Yao M, Bi HC, Lam S. Physiologically based pharmacokinetic modeling of tea catechin mixture in rats and humans. Pharmacol Res Perspect. 2017:5(3):e00305.

125. Way JC. Covalent modification as a strategy to block protein-protein interactions with small-molecule drugs. Curr Opin Chem Biol. 2000;4(1):40-6.

126. Smith AJ, Zhang X, Leach AG, Houk KN. Beyond picomolar affinities: quantitative aspects of noncovalent and covalent binding of drugs to proteins. J Med Chem. 2009;52(2):225-33.

127. Overington JP, Al-Lazikani B, Hopkins AL. How many drug targets are there? Nat Rev Drug Discov. 2006;5(12):993.

128. Copeland RA, Pompliano DL, Meek TD. Drug-target residence time and its implications for lead optimization. Nat Rev Drug Discov. 2006;5(9):730.

129. Brink A, Pähler A, Funk C, Schuler F, Schadt S. Minimizing the risk of chemically reactive metabolite formation of new drug candidates: implications for preclinical drug design. Drug Discov Today. 2017;22(5): 751-6.

130. González-Bello C. Designing irreversible inhibitors - worth the effort? Chem Med Chem. 2016;11(1):22-30
131. Baillie TA. The contributions of Sidney D. Nelson to drug metabolism research. Drug Metab. Rev. 2015;47(1):4-11.

132. Baillie TA. Targeted covalent inhibitors for drug design. Angew Chem Int Ed. 2016;55(43):13408-21.

133. Johnson DS, Weerapana E, Cravatt BF. Strategies for discovering and derisking covalent, irreversible enzyme inhibitors. Future Med Chem. 2010; 2(6):949-64.

134. Yu HS, Gao C, Lupyan D, Wu YJ, Kimura T, Wu CJ, et al. Towards atomistic modelling of irreversible covalent inhibitor binding kinetics. J Chem Inf Model. 2019;59(9):3955-67.

135. Goldman JL, Koen YM, Rogers SA, Li K, Leeder JS, Hanzlik RP. Bioactivation of trimethoprim to protein-reactive metabolites in human liver microsomes. Drug Metab Dispos. 2016;44(10):1603-7.

136. Yang Y, Shu YZ, Humphreys WG. Label-free bottom-up proteomic workflow for simultaneously assessing the target specificity of covalent drug candidates and their off-target reactivity to selected proteins. Chem Res Toxicol. 2016;29(1):109-16.

137. Wilson AJ, Kerns JK, Callahan JF, Moody CJ. Keap calm, and carry on covalently. J Med Chem. 2013;56(19):7463-76.

138. Carmi C, Lodola A, Rivara S, Vacondio F, Cavazzoni AR, Alfieri R, et al. Epidermal growth factor receptor irreversible inhibitors: chemical exploration of the cysteine-trap portion. Mini-Rev Med Chem. 2011;11(12): 1019-30.

139. Lonsdale R, Burgess J, Colclough N, Davies NL, Lenz EM, Orton AL, et al. Expanding the armory: predicting and tuning covalent warhead reactivity. J Chem Inf Model. 2017:57(12):3124-37.

140. Schwartz PA, Kuzmic P, Solowiej J, Bergqvist S, Bolanos B, Almaden C et al. Covalent EGFR inhibitor analysis reveals importance of reversible interactions to potency and mechanisms of drug resistance. Proc Natl Acad Sci 2014;111(1):173-178.

\section{Publisher's Note}

Springer Nature remains neutral with regard to jurisdictional claims in published maps and institutional affiliations.

Ready to submit your research? Choose BMC and benefit from

- fast, convenient online submission

- thorough peer review by experienced researchers in your field

- rapid publication on acceptance

- support for research data, including large and complex data types

- gold Open Access which fosters wider collaboration and increased citations

- maximum visibility for your research: over $100 \mathrm{M}$ website views per year

At $\mathrm{BMC}$, research is always in progress.

Learn more biomedcentral.com/submissions 